\section{HPV GENOTYPES}

Human papillomaviruses (HPVs) are categorized into genotypes according to the extent of sequence divergence in genes that are conserved between different isolates (in particular the $\mathrm{L} 1$ capsid gene), and genotypes are organized into broad clades of related sequence and, in general, related biology.

Centre for Immunology and Cancer Research, The University of Queensland, Princess Alexandra Hospital, Ipswich Road,

Woolloongabba,

Queensland 4102, Australia. e-mail:ifrazer@cicr.uq. edu.au

doi:10.1038/nri1260

\title{
PREVENTION OF CERVICAL CANCER THROUGH PAPILLOMAVIRUS VACCINATION
}

Ian H. Frazer

A subset of human papillomaviruses (HPVs) promote anogenital malignancy, including cervical cancer, and prevention and treatment strategies that reflect the causal role of HPV are being developed. Vaccines based on HPV virus-like particles induce genotype-specific virusneutralizing antibody and prevent infection with $\mathrm{HPV}^{1}$. Persistent papillomavirus infection is required for the development of papillomavirus-associated cancer and, therefore, therapeutic vaccines are being developed to eliminate established papillomavirus infection. Such vaccines test principles for the growing field of tumour-antigen-specific immunotherapy. This article reviews progress in the field and draws conclusions for the development of future prophylactic and therapeutic viral vaccines.

Globally, cervical cancer is one of most common cancers in women, killing about 0.25 million women per year. Cervical cancer (BOX 1) is attributed to persistent infection with a 'high-risk' subset of human papillomaviruses (HPVs) (TABLE 1), and is the first cancer recognized by the World Health Organization (WHO) to be $100 \%$ attributable to an infection ${ }^{2}$. At present, optimal treatment of cervical cancer combines surgery or radiotherapy with adjuvant chemotherapy, and delivers cure rates of almost $100 \%$ for locally invasive Federation of International Gynaecologists and Obstetricians (FIGO) stage 1 disease. Disease that has spread beyond the pelvis - FIGO stage 4 - is not generally regarded as curable, and many patients present with stage 4 disease in the developing world. Prevention and early detection of cervical cancer relies on cytology screening programmes, which have markedly reduced cervical cancer death rates where they are available. However, more than $80 \%$ of cervical cancer occurs in the developing world, where neither population-based screening nor optimal treatment is available. Further, present treatments and to a large extent present screening strategies do not acknowledge the viral aetiology of this common cancer.

\section{The link between cervical cancer and HPV}

Several cancers are now attributed, in part, to the consequences of chronic viral or bacterial infection. For example, the most successful available cancer vaccine prevents hepatocellular cancer that results from chronic infection with hepatitis B virus $(\mathrm{HBV})^{3}$. The crucial observation by Zur Hausen ${ }^{4}$ that infection with papillomavirus might be responsible for cervical cancer in humans was subsequently confirmed through long-term cross-sectional and case-controlled epidemiological studies. Their conclusions are supported by in vitro studies, showing the probable molecular mechanisms by which infection with HPV promotes epithelial cell immortalization and initiates the development of cervical cancer ${ }^{5}$.

Only a minority of HPV GENOTYPES infect the anogenital epithelium, and most of these infections are self limiting. However, persisting infection of the anogenital epithelium - over five years to a lifetime - with one of the more than ten high-risk genotypes of HPV is causally linked to cervical cancer, and other anogenital malignancies are also, to some degree, caused by HPV infection. Infection with HPV16 - the highest risk genotype - is responsible for more than $50 \%$ of 


\section{Box 1 | Cervical cancer}

- The second most common cancer in women worldwide

-250,000 new cases each year, commonly in 30-50-year-old women

- A consequence of infection with mucosal high-risk human papillomavirus (HPV)

- Preceded by many years of persistent HPV infection

- Premalignant lesions (cervical intraepithelial neoplasia, CIN) develop early after infection

- CIN and invasive cancers have integrated HPV DNA and express viral proteins

- Some genetic predisposition (MHC association - HLA-DQ $\beta$ locus, racial)

- Increased incidence after immunosuppression (HIV infection or immunosuppressive drugs)

- Contribution of environmental factors (smoking or oral contraceptive use) is controversial

\section{Prevention and treatment}

- Largely prevented by cervical cytology screening programmes

- Early stage (local) disease is curable by surgery and radiotherapy

- Later stage disease kills by local invasion rather than distant metastatic disease

- Some benefits from chemotherapy together with surgery and radiotherapy

cervical cancers worldwide ${ }^{6}$. Nevertheless, more than 95\% of incident HPV infections of the anogenital tract resolve over three to five years ${ }^{7}$, and cancer can be estimated to develop in less than 5\% of HPV16-infected individuals over their lifetime ${ }^{8}$.

\section{The biology of HPV infection}

Papillomaviruses are double-stranded DNA viruses (FIG. 1), which replicate exclusively in stratified squamous epithelia, using the differentiation of the epithelium to regulate their replication (FIG. 2). Virions penetrate the epithelium through microabrasions and infect epithelial stem cells that are located in the basal epithelial cell layer. In these cells and their progeny, known as transit amplifying cells, they replicate their DNA episomally, using two virus-encoded non-structural proteins, early 1 (E1) and E2, and the cellular DNA-replication machinery. Transit amplifying cells populate the basal layer of the epithelium. Expression of the viral E6 and E7 non-structural proteins delays cell-cycle arrest and differentiation, which is normally observed as epitheial cells move up from the basement membrane to become mature keratinocytes. This delay of cell-cycle arrest allows further viral episome replication using the host
DNA-replication machinery in suprabasal epithelial cells, and produces the thickening of the skin (or wart) characteristic of some papillomavirus infections. When the differentiation of replicating epithelial cells to nonreplicating mature keratinocytes eventually occurs, virus-encoded structural proteins, late 1 (L1) and L2, are assembled in the cell nucleus. Mature virions then assemble and are released from the epithelium within the superficial epithelial cells.

Infection with high-risk HPV sometimes results in integration of the viral episome into host DNA. If integration interrupts the viral E2 gene, overexpression of E6 and E7 proteins occurs owing to loss of E2-mediated repression of transcription of these genes. As a result, HPV-infected cells with integrated HPV DNA acquire extended lifespans, retain the capacity to proliferate, and tend to develop and perpetuate mutations in the germline DNA attributable to the actions of E6 and E7 proteins. Such cells are dysplastic, and marked dysplasia of the cervical epithelium is the precursor lesion of cervical malignancy, although dysplasia and infection might resolve spontaneously (see later).

\section{The natural immune response to HPV}

Resolution of HPV infection involves specific immune responses, as immunosuppression in transplant recipients ${ }^{9}$ or patients infected with $\mathrm{HIV}^{10}$ prevents the resolution of anogenital HPV infection and increases the risk of progression of HPV infection to malignancy. The natural immune response to HPV after infection is however weak, when compared with that of most other viral infections ${ }^{11}$ (BOX 2). There is little tissue destruction associated with HPV infection, and no virus-associated double-stranded RNA to invoke innate immune responses and initiate specific adaptive immunity. Papillomaviruses would, therefore, seem able to evade the immune responses of their mammalian hosts by avoiding the main triggers that initiate an immune response to viral infection - the host remains immunologically ignorant of the infection. In confirmation of this, natural immune responses to primary HPV infection are slow to appear, even though the viral proteins, if delivered optimally with adjuvants, are immunogenic in animals, as well as in uninfected and infected humans (see later). Papillomavirus functions provide additional potential mechanisms for evading the induction of immune responses and immune

\begin{tabular}{|c|c|c|c|c|c|}
\hline Group & Prototypes & Site of infection & Acute consequences & Chronic consequences & Other features \\
\hline Cutaneous & $\begin{array}{l}\text { HPV1, HPV2, } \\
\text { BPV1 }\end{array}$ & Skin & Warts & None & $\begin{array}{l}\text { Synchronous regression, lasting } \\
\text { immunity }\end{array}$ \\
\hline Mucosal & $\begin{array}{l}\text { HPV6, HPV11, } \\
\text { COPV, ROPV }\end{array}$ & Genital mucosa & Warts & None & $\begin{array}{l}\text { Slow resolution in immunosuppressed } \\
\text { individuals }\end{array}$ \\
\hline $\begin{array}{l}\text { Mucosal } \\
\text { high risk }\end{array}$ & $\begin{array}{l}\text { HPV16, HPV18, } \\
\text { HPV31, HPV33, } \\
\text { HPV45, BPV4 }\end{array}$ & $\begin{array}{l}\text { Anogenital mucosa } \\
\text { (other mucosal } \\
\text { surfaces) }\end{array}$ & Flat lesion (CIN 1) & $\begin{array}{l}\sim 2 \% \text { persist, } \sim 1 \% \text { progress } \\
\text { to invasive cancer }\end{array}$ & $\begin{array}{l}\text { Slow resolution in immunosuppressed } \\
\text { individuals, variable malignant } \\
\text { potential }\end{array}$ \\
\hline $\begin{array}{l}\text { Cutaneous } \\
\text { high risk }\end{array}$ & $\begin{array}{l}\text { HPV5, HPV8, } \\
\text { CRPV }\end{array}$ & Skin & $\begin{array}{l}\text { Flat lesion or none } \\
\text { Warts }\end{array}$ & Promotes SCC (?) & $\begin{array}{l}\text { SCC more common in } \\
\text { immunosuppressed individuals }\end{array}$ \\
\hline
\end{tabular}

BPV, bovine papillomavirus; CIN, cervical intraepithelial neoplasia; COPV, canine oral papillomavirus; CRPV, cottontail rabbit papillomavirus; DTH, delayed-type hypersensitivity; HPV, human papillomavirus; ROPV, rabbit oral papillomavirus; SCC, squamous skin cancer. 
effector mechanisms ${ }^{12}$. The E6 protein inhibits epithelial-cell-dendritic-cell interactions ${ }^{13}$, perhaps accounting for the depletion of dendritic cells observed in the HPVinfected cervical epithelium ${ }^{14}$. The E6 and E7 proteins block the production of and responsiveness of infected cells to type 1 interferons (IFNs) ${ }^{15-18}$. The E5 protein inhibits $\mathrm{pH}$-dependent processing of antigenic peptides ${ }^{19}$. Evaluation of the significance of these mechanisms for viral immune evasion awaits the production of function-deficient infectious virions.

Antibodies specific for the HPV16 L1 major capsid protein (the most readily detectable virus-specific immune response) develop four months to five years after the first infection, although one-third to one-half of women develop no measurable capsid-specific antibody response at $\mathrm{all}^{20}$. Antibodies specific for the E7 nonstructural protein appear only with the onset of invasive cervical cancer ${ }^{21}$, even though the protein is expressed in acute infection and during the 10-20 year progression of chronic infection to invasive malignancy. Whether the immune response, which eventually results in natural infection in some people, protects the host from further viral challenge is hard to establish. However, cows ${ }^{22,23}$, rabbits ${ }^{24}$ and $\operatorname{dog} s^{25}$ infected or immunized with their species-specific papillomaviruses develop neutralizing antibodies, and seem resistant to further viral challenge, indicating that protective immunity can develop after successful resolution of primary infection. Cell-mediated immune responses to papillomavirus proteins following natural infection in humans have been harder to define, mainly for technical reasons that relate to the probable low frequency of circulating effector cells. However, regression of papillomavirus-associated lesions in humans, as in animals, is associated with a cellular infiltrate of $\mathrm{T}$ cell $\mathrm{s}^{26,27}$; there is presumptive evidence of specific cellular immune responses to at least some viral non-structural proteins ${ }^{28,29}$, and one study indicates that delayed-type hypersensitivity to the viral E7 protein correlates with resolution of clinical disease ${ }^{30}$.

\section{Vaccines for HPV infection}

Viral vaccines that are presently licensed for use in humans are prophylactic against future challenge with infectious virus. It is believed that all prophylactic vaccines work through the induction of virus-neutralizing antibodies, and markedly reduce the number of cells that are infected after challenge with virus, and so prevent the clinical disease associated with infection. Successful vaccines immunologically mimic the infections they prevent, priming the adaptive immune system to recall specific effector functions ('memory') to future encounters with the infectious agent, and this restimulation on challenge boosts immunity and, therefore, protection against future viral challenge.

Vaccines might also be developed to eradicate cells that are already infected with virus. Such vaccines, known as therapeutic vaccines, would be designed to prime the antigen-specific T-cell-mediated effector mechanisms that are used by the host immune system to control and eradicate viral infections. These include $\mathrm{CD}^{+}$T-cell-mediated cytotoxicity targeted at infected

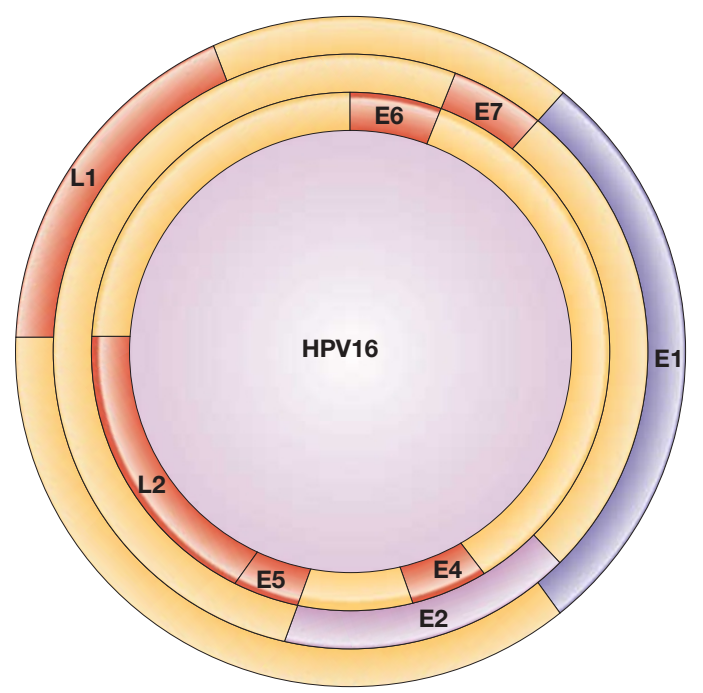

Figure 1 | Schematic of the human papillomavirus 16 (HPV16) genome showing the arrangement of the major non-structural and capsid genes. The three circles correspond to the three reading frames in which the sense strand can be translated. There are no known gene products produced from the antisense strand. Viral protein early 4 (E4) is encoded by a messenger RNA transcript that includes the initial amino acids of the $E 1$ gene. The region between late $1(\mathrm{~L} 1)$ and $\mathrm{E} 6 \mathrm{is}$ an important transcriptional regulatory region - the mRNAs encoding most nonstructural (E6, E7, E1, E2, E4 and E5) and capsid (L1 and L2) genes originate in this region. Most papillomavirus genomes resemble HPV16 in general organization.

cells, and secretion by T cells of cytokines with direct (IFN- $\alpha$ and IFN- $\gamma$ ) or indirect (interleukin-1 (IL-1) or IL-12) effects on virus-infected cells. If a virus-specific effector T-cell response were present during initial viral challenge, as a consequence either of recent immunization or of stimulation by viral antigens of memory cells induced by previous immunization, then early termination of viral replication might prevent disease. If the effector T-cell responses were stimulated when viral pathology was already present, therapeutic elimination of infected cells and, therefore, of disease would be the goal.

\section{HPV prophylactic vaccines}

As discussed earlier, the main effector mechanism for vaccine-induced prevention of viral infection is neutralizing antibody. Pioneering studies by Jarrett and colleagues $^{31}$ used formalized bovine papillomavirus virions as a vaccine, and these studies showed that vaccination could be used to induce papillomavirusspecific antibodies and prevent infection with virus. However, replication of papillomavirus requires epithelial cell differentiation to allow the production of viral capsid proteins $s^{32,33}$, as described earlier, and this prevents conventional approaches to the production of virus for vaccines in continuous cell culture in vitro. Although systems have recently been developed that allow recapitulation of the entire papillomavirus lifecycle in epithelial cell raft culture ${ }^{34}$ and in yeast ${ }^{35}$, the yield from these culture systems is insufficient to generate a conventional killed vaccine. 


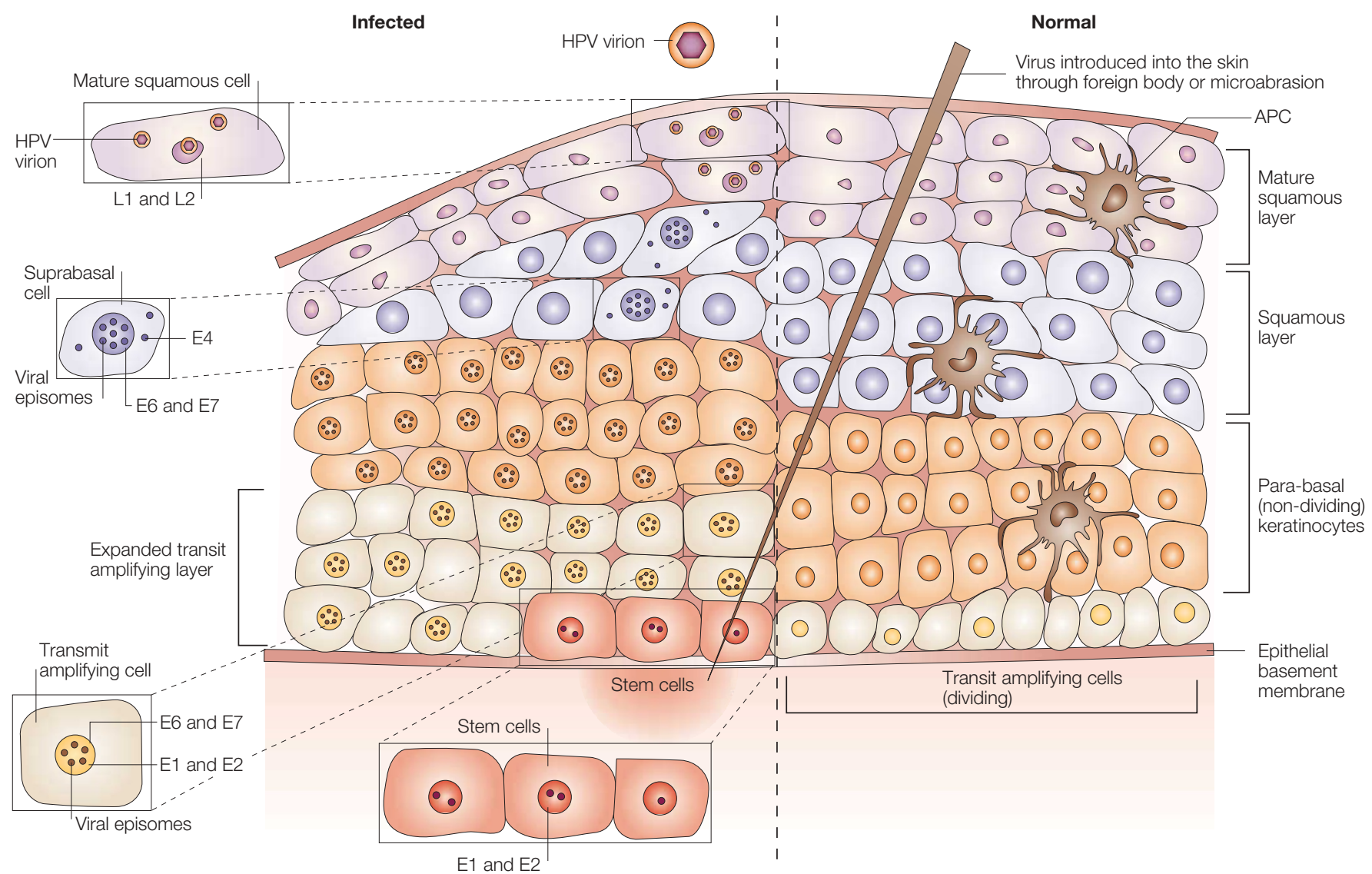

Figure 2 | The location in squamous epithelium of the main stages of the papillomavirus life cycle. Cervical stratified squamous epithelial cell architecture and the expression of human papillomavirus (HPV) proteins after infection. Daughter cells of epithelial stem cells divide along the basement membrane and then mature vertically through the epithelium without further division (right side). After introduction of HPV into stem cells in the basal layer of the epithelium, expression of viral non-structural proteins occurs. Under the regulation of these proteins, the dividing-cell population expands vertically and epithelial cell differentiation is delayed and is less complete. Viral proteins are expressed sequentially with differentiation as shown, and mature virions are produced only in the most superficial layers of the epithelium. Intraepithelial antigen-presenting cells (APCs) are depleted in the HPV-infected epithelium.

Virus-like particles. Recombinant DNA technology allows expression of the L1 major capsid protein of papillomavirus (TABLE 2) by various cell types, and expression of L1 protein by eukaryotic cells is followed by self assembly of the recombinant L1 into VIRUS-LIKE PARTICLES (VLPs) ${ }^{36,37}$. L1 VLPs mimic the natural virus structurally and, unlike denatured L1 protein, elicit high titres of virus-neutralizing antibodies in animals and humans. Although the amino-acid sequence of L1 is conserved between HPV genotypes, most genotypes seem to be serotypically distinct. An explanation for this observation was provided by definition of the crystal structure of the L1 molecule as assembled in VLP pentamers $^{38}$. Variability between papillomavirus genotypes is concentrated over a few amino acids in the solventfacing apices of three loops of the $\sim 500$ amino-acid L1 peptide chain; these loops contain the sites to which neutralizing antibodies are directed. In keeping with this observation, vaccines based on papillomavirus VLPs seem to offer genotype-specific protection against infection with papillomavirus in animals and humans. Passive-transfer studies in animals have shown that antibody is sufficien $t^{39}$ to provide host protection against papillomavirus infection after VLP immunization.
Two important randomized placebo-controlled studies ${ }^{1,40}$ on young sexually active women have shown that vaccination with HPV16 VLPs induces absolute protection over 12-18 months against persisting infection with HPV16, in association with high and persisting titres of neutralizing antibody specific for the virus, and similar protection against virus-associated premalignant lesions of the cervix. Interestingly, both studies have shown a lower incidence, but not prevention, of transient cervical infection in immunized individuals than in controls. As increased risk of cervical cancer is associated with persistent infection, transient infection in immunized individuals is unlikely to be of clinical consequence. Immunologically, however, the observation that immunization reduces the incidence of transient infection, but absolutely prevents persistent infection is puzzling. As protection is antibody dependent and immunization with VLPs with conventional alum adjuvants mainly induces an antibody response, a possible explanation is that transient infection results from infection of more superficial cells in the cervical epithelium, which are less protected by systemic antibody, and which have a defined and short lifespan. Epithelial stem cells are self renewing, and therefore infection of these 


\section{Box 2 | Why human papillomavirus is a poor natural immunogen}

- Human papillomavirus (HPV) is a double-stranded DNA virus with no doublestranded RNA intermediate to invoke innate immune responses.

- HPV mainly encodes non-secreted nucleoproteins, which are not effectively crosspresented by infected cells.

- Most viral non-structural proteins are expressed at low levels compared with more immunogenic proteins from other viruses.

- The virus only infects epithelial cells — an anti-inflammatory environment (interleukin-10 and transforming growth factor- $\beta$ predominate).

- Infection induces cell proliferation rather than cytolysis, without danger signals or antigen release to invoke innate immunity.

- Infection has no viraemic phase, as infected cells do not undergo lysis as a result of infection, and therefore less systemic antigen presentation occurs.

CERVICAL INTRAEPITHELIAL NEOPLASIA

(CIN). Cervical epithelium that has abnormal cellular

architecture (nuclear irregularities, altered

nuclear/cytoplasmic ratio and abnormal mitoses), and/or

abnormal epithelial architecture (abnormal differentiation, increased mitotic activity and abnormal cellular orientation). CIN is commonly seen at the junction between the squamous and the columnar epithelium of the cervix (known as the 'transformation zone') and in association with cellular evidence of papillomavirus infection (koilocytosis). Graded from I to III for severity. cells is more likely to produce persistent infection. As these cells lie deeper in the epithelium they would be more exposed to systemic virus-neutralizing antibody. Although VLP-based vaccines induce both systemic and mucosal immunity ${ }^{41}$, the relative contribution of each to protection is undefined, yet these data indicate that antibody might have a particular role in protecting cells that are vulnerable to persisting infection.

Protection against HPV-associated diseases after VLP vaccination is genotype specific in animals, and antibody induced by VLP-based vaccines efficiently neutralizes in vitro only the genotype to which the antibody was raised ${ }^{42}$. Prophylactic vaccines that are envisaged at present incorporate two high-risk genotypes of HPV (HPV16 and HPV18), which together account for about $70 \%$ of cervical cancers ${ }^{6}$. If vaccine-induced protection is genotype specific in humans, vaccines presently under trial will, at best, prevent only twothirds of cervical cancer in successfully immunized women. Further clinical trials will define the duration of immunity to HPV infection after immunization of healthy and immune compromised men and women, and children prior to sexual activity, and so will better define the role and optimal use of these vaccines as part of the various strategies available for the prevention of cervical cancer. Follow-up studies on immunized individuals might also define the pathogenic significance of HPV infection for cancers, in which the causal role of oncogenic HPV infections remains controversial, including oesophageal and oral cancers.

\section{HPV therapeutic vaccines}

Animal models have recently confirmed a role for specific immunity in cancer surveillance ${ }^{43}$. Cervical cancer is the only human cancer that is $100 \%$ attributable to infection with a virus - human papillomavirus — and the cancer and its precursor lesion, CERVICAL INTRAEPITHELIAL NEOPLASIA (CIN), continue to express defined viral proteins (TABLE 1). HPV infection should, therefore, be an optimal 'test case' for the probable effects of immunological intervention to prevent or treat a human cancer, as it meets many of the requirements for successful specific immunotherapy (BOX 3).

VLP-based prophylactic vaccines might be able to prevent infection with high-risk HPV, if delivered to women before exposure to the virus. But even if prophylactic vaccination were to begin today, there is nevertheless a compelling case for developing immunotherapy for existing HPV infection, as this has the potential to prevent the estimated 5 million cervical cancer deaths that will otherwise occur over the next 20 years as a consequence of existing HPV infections. Immunotherapy could have an immediate impact on the incidence of cervical cancer, whereas prophylactic vaccines will take many years to reduce deaths from this disease. Cervical cancer cells and cells of the premalignant anogenital epithelial lesions that arise from chronic HPV infection express up to eight papillomavirus-encoded proteins (L1, L2 and E1-E7) (TABLE 2). E2, E6 and E7 proteins are of particular interest for vaccine development at present. The E7 protein seems to induce protective cellular immunity

\begin{tabular}{|c|c|c|c|c|}
\hline Protein & Group & $\begin{array}{l}\text { Cellular } \\
\text { localization/amount }\end{array}$ & Function & Natural immune response \\
\hline L1 & Late & Nuclear/++++ & $\begin{array}{l}\text { Major capsid protein } \\
\text { (structural) }\end{array}$ & $\begin{array}{l}\text { Antibody in } 50-100 \% \text { of infected humans, } \\
\text { occurring weeks to years after infection }\end{array}$ \\
\hline L2 & Late & Nuclear/++ & $\begin{array}{l}\text { Minor capsid protein } \\
\text { Assists packaging of DNA }\end{array}$ & None \\
\hline E1 & Early & Nuclear/+ & $\begin{array}{l}\text { Assists episomal replication } \\
\text { DNA helicase }\end{array}$ & None \\
\hline E2 & Early & Nuclear/+ & Transcription factor & $\begin{array}{l}\text { Cellular responses associated with regressing } \\
\text { lesions in infected animals }\end{array}$ \\
\hline E4 & Late & Cytoplasmic/+++ & Assists packaging of virus (?) & None \\
\hline E5 & Early & Cytoplasmic/+ & $\begin{array}{l}\text { Prevents cell differentiation } \\
\text { (more important for BPV } \\
\text { than HPV) }\end{array}$ & None \\
\hline E6 & Intermediate & Nuclear/+ & $\begin{array}{l}\text { Prevents cell differentiation } \\
\text { Promotes p53 degradation }\end{array}$ & \\
\hline E7 & Intermediate & Nuclear/++ & $\begin{array}{l}\text { Prevents cell-growth arrest/ } \\
\text { differentiation - inhibits } \\
\text { inhibitors of E2F transcription } \\
\text { factor }\end{array}$ & $\begin{array}{l}\text { DTH associated with regressing CIN lesions } \\
\text { in humans. Antibody associated with } \\
\text { invasive cervical cancers in humans }\end{array}$ \\
\hline
\end{tabular}

BPV, bovine papillomavirus; CIN, cervical intraepithelial neoplasia; DTH, delayed-type hypersensitivity; HPV, human papillomavirus. 


\section{Box 3 | Requirements for successful specific immunotherapy}

Target cell

- Transcribes and translates a relevant protein antigen

- Protein is accessible to peptide-processing machinery

- Protein incorporates epitopes that can be presented by relevant MHC molecules

- Intact and uninhibited antigen-processing pathway (including MHC presentation)

- Protein ineffectively cross-presented for induction of immunity (or there would be no need for immunotherapy)

- Susceptible to effector mechanisms (such as apoptosis and terminal differentiation)

- Does not secrete or express local inhibitors of effector function

Immune effector system

- Naive T cells with appropriate T-cell receptors for target antigen

Intervention (vaccination) induces

- Sufficient quantity of effector cells

- Trafficking to target tissue

- Appropriate effector mechanisms

- Responses of sufficient duration in human premalignancy ${ }^{30}$. The E7 protein also induces genotype-specific antibody after the onset of invasive cervical cancer ${ }^{21}$, although this immune response is clearly not host protective.

\section{Animal models of therapy for HPV infection}

Papillomavirus infections have been studied in several animals and have shed light on HPV immunology and immunotherapy. Animal infections, including bovine papillomavirus (BPV), cottontail rabbit papillomavirus (CRPV), canine oral papillomavirus and rabbit oral papillomavirus, have allowed detailed study of the natural immune response to infection with papillomavirus, and have been crucial in defining the use of prophylactic vaccination. Most animal papillomavirus infections are, in contrast to high-risk HPV infections, rapidly self limiting, induce strong immune responses that protect against further infection and do not promote malignancy. The natural regression of these lesions is thought to reflect expression, early in epithelial cell differentiation, of the viral late proteins and a consequent better natural immune response to infection ${ }^{44}$. Some animal papillomavirus infections (BPV1, BPV4 and CRPV) more closely resemble high-risk HPV infections, with general resolution but occasional persistence and risk of malignancy; the risk of progression being, in part, genetically determined and MHC linked ${ }^{45}$, as is also observed in humans ${ }^{46}$. Immunotherapy, targeted at virus-encoded structural and non-structural proteins, can modulate the course of disease in each of these animal infections, if given early after viral challenge and before the onset of lesions. For self-limiting infections, the E2 protein seems an effective target. For persisting infections, the best result, perhaps unsurprisingly, occurs after administration of a vaccine based on all of the viral non-structural proteins ${ }^{47}$.

A range of mouse transplantable tumours have been engineered that express papillomavirus proteins. These tumours are generally susceptible to a wide range of specific and non-specific immunotherapeutic approaches ${ }^{48}$. These include polynucleotide vaccines $^{47,49-51}$; viral ${ }^{52,53}$ and bacterial ${ }^{54}$ vectors that express various viral non-structural proteins; and protein- ${ }^{55}$ or peptide-based ${ }^{56}$ immunogens, either incorporating innate immune stimulants (such as heat-shock protein ${ }^{57}$ ) or delivered with adjuvants that are designed to promote cell-mediated immune responses ${ }^{58}$. Cell-based therapy with antigen-primed dendritic cells has also proven to be effective in these animal models ${ }^{59}$. Effective immunotherapy administered before tumour challenge includes an antigen-specific component, whereas effective immunotherapy after tumour challenge can be achieved with enhancement of either innate or adaptive immunity, and seems to be optimal with both ${ }^{60}$. Rejection depends on antigen-specific $\mathrm{CD}^{+} \mathrm{T}$ cells ${ }^{61}$ and the induction of memory, and recall responses are determined by the generation of concomitant CD4 $4^{+} \mathrm{T}$-cell responses ${ }^{61,62}$. Immunotherapeutic approaches used, with varying success, in human clinical trials (TABLE 3) have invariably proven to be effective in the transplantable tumour models, indicating that these models might be rather non-discriminatory for useful clinical products.

To explore more critically the role of immunotherapy for specific tumour-associated viral antigens, we established an animal model, in which skin expressing various papillomavirus antigens from a promoter (keratin 14, K14) that is active only in epithelial cells is transplanted into naive immunocompetent recipients ${ }^{63}$. This model shows that papillomavirus-encoded nuclear antigens, such as E6 and E7, invoke weak natural immune responses, which do not lead to graft rejection, in contrast to secreted antigens, such as ovalbumin $(\mathrm{OVA})^{64}$, which prime strong immune responses with ensuing rapid graft rejection. Enhancing innate immunity, through concomitant infection with Listeria monocytogenes ${ }^{65}$ or a range of viruses, promotes the rejection of newly placed, but not well-established, K14-E7-transgenic grafts. Rejection is antigen specific and induces long-lasting memory, preventing the establishment of further grafts. Rejection of K14-E7 grafts can also be achieved by passive transfer of specific $\mathrm{CD}^{+}$ $\mathrm{T}$ cells, activated in vivo by specific immunization, although not by immunization alone. Combined active/passive specific immunotherapy is, however, most effective for recently placed grafts. No therapy has yet been identified that reliably induces rejection of well-established grafts, even though these continue to express the E7 tumour antigen, which eventually promotes malignancy in the graft.

Taken together, these animal models indicate that high-risk HPV-encoded early proteins, such as nuclear antigens, are poorly cross-presented by epithelial cells to produce effective therapeutic immunity, and are poorly presented by epithelial cells to effector $\mathrm{T}$ cells induced through vaccination. Whether poor presentation reflects poor trafficking of effector cells to a skin target that lacks pro-inflammatory signals, or poor direct presentation by epithelial cells of relevant peptides in the context of MHC to effectors that reach the skin site of infection, or both, remains to be resolved. 
As E7-specific effector T cells cannot kill E7-expressing keratinocytes in vitro, whereas the same E7-specific effector T cells can kill most E7-expressing cell lines, and can also kill keratinocytes that are exposed to the relevant E7 peptide, processing of endogenous antigen for direct presentation by keratinocytes to $\mathrm{T}$ cells might be faulty ${ }^{66}$. As large numbers of primed antigen-specific $\mathrm{T}$ cells achieve skin-graft rejection in vivo, whereas small numbers can achieve transplantable tumour rejection, directing effector cells to traffic to skin targets might also be required for the development of an effective therapeutic vaccine for papillomavirus infection.

\section{Human trials of immunotherapy for HPV infection} Several possible immunotherapeutic interventions have been tested for cervical cancer and the preceding premalignant lesion (TABLE 3). Cervical cancers, unlike their preceding premalignant $\mathrm{HPV}$-induced lesions, express only two viral genes (E6 and E7) consistently as a result of selective integration of the papillomavirus genome into transformed cells. In general, trials for cervical cancer interventions have been carried out in patients with late-stage disease, who are already partially immune compromised by radiotherapy and/or chemotherapy. In addition, mutations and deletions in genes that are involved in antigen processing and presentation are commonly observed in cervical cancer cells ${ }^{67,68}$, indicating that these will be poor targets for specific immunotherapy (BOX 3). Despite these problems, specific cellular and humoral immunity has been induced in some immunized individuals, albeit with limited evidence of therapeutic benefit (TABLE 3). One practical problem is that there is little information available from previous successful immunotherapeutic interventions in humans about optimal dose and frequency of delivery of antigen, or about the choice of adjuvant. Repeated immunizations and presently licensed alum-based adjuvants tend to bias the resulting immune responses towards the production of antibody and $\mathrm{T}$ helper 2 $\left(\mathrm{T}_{\mathrm{H}} 2\right)$-type cytokines (IL-4 and IL-5), and away from cytotoxic $\mathrm{T}$ cells and $\mathrm{T}_{\mathrm{H}} 1$-type cytokines (IFN- $\gamma$ and tumour-necrosis factor) ${ }^{69,70}$ and consequently, are unlikely to be successful for eradicating tumour cells. Further, previous exposure to antigen as a result of infection with HPV might have already primed for ineffective $\mathrm{T}_{\mathrm{H}}$ 2-biased immune responses ${ }^{69}$.

\section{Table 3 | Clinical trials of HPV-specific immunotherapy}

\begin{tabular}{|c|c|c|c|c|c|}
\hline Delivery system & Antigen & Disease group & Immunogenicity & Clinical outcome & Refs \\
\hline $\begin{array}{l}\text { Fusion protein } \\
\text { (TA-CIN, Xenova) }\end{array}$ & $\begin{array}{l}\text { HPV16 } \\
\text { L2-E6-E7 } \\
\text { fusion protein } \\
\text { (no adjuvant) }\end{array}$ & Healthy volunteers & $\begin{array}{l}\text { Antibody, T-cell proliferation, } \\
\text { IFN- } \gamma \text { ELISPOT all detected }\end{array}$ & $\begin{array}{l}\text { Double-blind placebo-controlled trial } \\
\text { No HPV infections }\end{array}$ & 74 \\
\hline $\begin{array}{l}\text { HSP fusion protein } \\
\text { (HSP-E7, Stressgen) }\end{array}$ & HPV16 E7 & Genital warts & N.D. & $\begin{array}{l}\text { Regression of warts: } 3 / 14 \text { CRs and } \\
\text { 10/14 PRs. Warts not HPV16+ } \\
\text { Open-label uncontrolled trial }\end{array}$ & 75 \\
\hline $\begin{array}{l}\text { Encapsulated } \\
\text { polynucleotide } \\
\text { (ZYC101, Zycos) }\end{array}$ & $\begin{array}{l}\text { HPV16 E7 } \\
\text { peptide }\end{array}$ & $\begin{array}{l}\text { Anal dysplasia } \\
\text { Cervical dysplasia }\end{array}$ & $\begin{array}{l}\text { Most individuals ELISPOT positive } \\
\text { Induction of E2-specific immunity }\end{array}$ & $\begin{array}{l}\text { HPV16 }{ }^{+} \text {by selection } \\
\text { Open-label uncontrolled trials } \\
\text { Regression of AIN: 3/12 PRs } \\
\text { Regression of CIN: 5/15 CRs }\end{array}$ & 76,77 \\
\hline $\begin{array}{l}\text { Protein/Iscomatrix } \\
\text { adjuvant } \\
\text { (E6E7-IMX, CSL) }\end{array}$ & $\begin{array}{l}\text { HPV16 E6-E7 } \\
\text { fusion protein }\end{array}$ & CIN & Antibody, DTH, CTLs & $\begin{array}{l}\text { HPV-type-specific reduction in HPV } \\
\text { infection: } 7 / 14 \mathrm{CR} \text { s and } 7 / 14 \mathrm{PRs} / \mathrm{no} \\
\text { clinical regression } \\
\text { Randomized placebo-controlled trial }\end{array}$ & 86 \\
\hline $\begin{array}{l}\text { Vaccinia virus } \\
\text { (TA-HPV, Xenova) }\end{array}$ & $\begin{array}{l}\text { E6-E7 fusion } \\
\text { protein }\end{array}$ & Cervical cancer & CTLs (1/8), antibody (3/8) & $\begin{array}{l}\text { Outcome not documented } \\
\text { Open-label uncontrolled trial }\end{array}$ & 78 \\
\hline $\begin{array}{l}\text { Vaccinia virus } \\
\text { (TA-HPV, Xenova) }\end{array}$ & $\begin{array}{l}\text { E6-E7 fusion } \\
\text { protein }\end{array}$ & Vulval HPVNIN & Antibody, CMI (13/18) & $\begin{array}{l}50 \% \text { reduction in disease in } 8 / 18 \\
\text { Loss of viral load in } 12 / 18 \\
\text { Open-label uncontrolled trial }\end{array}$ & 79 \\
\hline $\begin{array}{l}\text { Vaccinia virus } \\
\text { (TA-HPV, Xenova) }\end{array}$ & $\begin{array}{l}\text { E6-E7 fusion } \\
\text { protein }\end{array}$ & VIN & $\begin{array}{l}\text { Thelper cell ELISPOT increase }(6 / 10) \\
\text { Vaccinia response in all subjects }\end{array}$ & $\begin{array}{l}>50 \% \text { reduction in disease in } 5 / 12 \\
\text { Open-label uncontrolled trial }\end{array}$ & 80 \\
\hline $\begin{array}{l}\text { Peptide/oil + } \\
\text { water adjuvant }\end{array}$ & E7 peptides & Cervical cancer & No CTL response & $\begin{array}{l}\text { HPV } 16^{+} \text {by selection } \\
\text { Outcome } 2 / 17 \mathrm{SD} \\
\text { Open-label uncontrolled trial }\end{array}$ & 81 \\
\hline $\begin{array}{l}\text { Protein/algammulin } \\
\text { adjuvant }\end{array}$ & $\begin{array}{l}\text { E7-GST } \\
\text { fusion protein }\end{array}$ & Cervical cancer & Antibody, DTH & $\begin{array}{l}\text { No alteration in natural history of } \\
\text { disease. Open-label uncontrolled trial }\end{array}$ & 82 \\
\hline Peptide + IFA & $\begin{array}{l}\text { E7 A0201 } \\
\text { peptide }\end{array}$ & VIN/CIN & CTLs 10/16, no DTH & $\begin{array}{l}\text { HPV } 16^{+} \text {by selection } \\
3 / 18 \text { CRs and } 6 / 18 \text { PRs } \\
\text { Open-label uncontrolled trial }\end{array}$ & 83 \\
\hline VLPS & L1 & Genital warts & Antibody, DTH & $\begin{array}{l}\text { Regression of warts: } 25 / 33 \text { CRs } \\
\text { Open-label uncontrolled trial }\end{array}$ & 84 \\
\hline Dendritic cells & $\begin{array}{l}\text { HPV16 E7 } \\
\text { and HPV18 E7 }\end{array}$ & Cervical cancer & $\begin{array}{l}\text { Antibody, proliferation, } \\
\text { ELISPOT (3/11) }\end{array}$ & $\begin{array}{l}\text { No objective clinical response } \\
\text { Open-label uncontrolled trial }\end{array}$ & 85 \\
\hline
\end{tabular}

AIN, anal intraepithelial neoplasia; CIN, cervical intraepithelial neoplasia; CMI,cell-mediated immunity; CR, complete response; CTL, cytotoxic T lymphocyte; DTH, delayed-type hypersensitivity; E, early; ELISPOT, enzyme-linked immunospot; GST, glutathione S-transferase; HPV, human papillomavirus; HSP, heat-shock protein; IFA, incomplete freund's adjuvant; IFN- $\gamma$, interferon- $\gamma$; L, late; N.D., not determined; PR, partial response; SD, stable disease; TA, therapeutic antigen; VIN, vulval intraepithelial neoplasia; VLP, virus-like particle. 
Trials of immunotherapy in patients with HPVassociated premalignancy are more likely to be informative, as the cancer-associated immunosuppressive mechanisms, of which the most relevant is impaired antigen presentation by cervical cancer cells as a consequence of mutations in MHC and TAP genes ${ }^{72,73}$, are unlikely to be of relevance, although there are potential immune-evasive mechanisms that are attributable to $\mathrm{HPV}$ infection itself ${ }^{71}$. Induction of specific immunity to papillomavirus early proteins can be achieved by several antigen-delivery systems, including saponin and enhanced oil in water emulsion adjuvants, recombinant viral vectors, heat-shock protein fusion proteins and polynucleotide antigen-expression systems. Clinical benefits are harder to define in these early phase clinical trials. Where these are indicated, they might, in part, reflect the induction of innate immunity, as the responses seen are not specific to disease caused by the papillomavirus genotype to which the vaccine is targeted. These results nevertheless justify pursuit of further randomized placebo-controlled trials, which might extend to trials of combined prophylactic and therapeutic vaccination to prevent and accelerate the elimination of early HPV infection.

\section{Conclusions and the future}

Vaccines to prevent infection with high-risk HPVs are conventional vaccines, inducing high titres of neutralizing antibodies, which provide host protection against infection and the potential malignant consequences of infection. Their use should follow ongoing Phase III studies of efficacy worldwide. Further studies with HPV VLP-based vaccines will be undertaken, which might broaden the range of HPV genotypes that are protected against and better define the duration of protection. These data will enable the rational introduction of these vaccines to appropriate target groups of young women before the onset of sexual activity. Educating healthcare professionals and public-health authorities about the benefits of the use of papillomavirus vaccines in the developed and developing world will require better definition of the local prevalence and natural history of HPV infections. As cervical cancer can largely be prevented by well-deployed cytology screening programmes, the interaction between a vaccine programme, which does not cover all papillomavirus genotypes and can protect against only $70 \%$ of cervical cancers, and a screening programme, which will probably find far fewer abnormalities for further management after vaccine introduction, will need careful planning.

Vaccines to treat persistent infections with papillomavirus are experimental. There is a need to define effective methods to overcome the challenges imposed by, on the one hand, poor presentation of viral nucleoprotein antigens that are expressed at low levels and, on the other hand, poor trafficking of effector T-cell populations to non-inflamed skin sites. However, papillomavirus-specific immune responses can be induced in humans, enhancement of innate immunity seems to assist the natural resolution of persistent infection with papillomavirus, and vaccines that promote trafficking of effectors preferentially to the skin are under development, allowing cautious optimism that effective immunotherapy for papillomavirus infection can be achieved.
1. Koutsky, L. A. et al. A controlled trial of a human papillomavirus type 16 vaccine. N. Engl. J. Med. $\mathbf{3 4 7}$ 1645-1651 (2002).

The first randomized placebo-controlled trial of the efficacy of a virus-like particle (VLP)-based vaccine in preventing infection with a 'high-risk' human papillomavirus (HPV), showing $100 \%$ efficacy at preventing persistent HPV infection in young, preventing persistent HPV infectio
previously uninfected women.

2. Bosch, F. X., Lorincz, A., Munoz, N., Meijer, C. J. \& Shah, K. V. The causal relation between human papillomavirus and cervical cancer. J. Clin. Pathol. 55, 244-265 (2002).

3. Chang, M. H. et al. Hepatitis B vaccination and hepatocellular carcinoma rates in boys and girls. JAMA 284, 3040-3042 (2000)

4. Zur Hausen, H., de Villiers, E. M. \& Gissmann, L. Papillomavirus infections and human genital cancer. Gynecol. Oncol. 12, S124-S128 (1981).

5. Zur Hausen, H. Immortalization of human cells and their malignant conversion by high risk human papillomavirus genotypes. Semin. Cancer Biol. 9, 405-411 (1999).

6. Muñoz, N. et al. Epidemiologic classification of human papillomavirus types associated with cervical cancer. N. Engl. J. Med. 348, 518-527 (2003).

7. Schlecht, N. F. et al. Human papillomavirus infection and time to progression and regression of cervical intraepithelial neoplasia. J. Nat/ Cancer Inst. 95, 1336-1343 (2003).

8. Goldie, S. J. et al. A comprehensive natural history model of HPV infection and cervical cancer to estimate the clinical impact of a prophylactic HPV-16/18 vaccine. Int. J. Cancer 106, 896-904 (2003)

9. Sillman, F. H., Sentovich, S. \& Shaffer, D. Ano-genital neoplasia in renal transplant patients. Ann. Transplant. 2 59-66 (1997).

10. Ferenczy, A., Coutlee, F., Franco, E. \& Hankins, C. Human papillomavirus and HIV coinfection and the risk of neoplasias of the lower genital tract: a review of recent developments. CMAJ 169, 431-434 (2003).
11. Frazer, I. H. Immunology of papillomavirus infection. Curr. Opin. Immunol. 8, 484-491 (1996).

12. Tindle, R. W. Immune evasion in human papillomavirusassociated cervical cancer. Nature Rev. Cancer 2, 59-65 (2002).

13. Matthews, K. et al. Depletion of Langerhans cells in human papillomavirus type 16-infected skin is associated with E6-mediated downregulation of E-cadherin. J. Virol. 77, 8378-8385 (2003).

14. Tay, S. K., Jenkins, D., Maddox, P., Campion, M. \& Singer, A. Subpopulations of Langerhans cells in cervical neoplasia. Br. J. Obstet. Gynaecol. 94, 10-15 (1987).

15. Ronco, L. V., Karpova, A. Y., Vidal, M. \& Howley, P. M. Human papillomavirus $16 \mathrm{E} 6$ oncoprotein binds to interferon regulatory factor-3 and inhibits its transcriptional activity. Genes Dev. 12, 2061-2072 (1998).

16. Barnard, P. \& McMillan, N. A. J. The human papillomavirus E7 oncoprotein abrogates signaling mediated by interferon- $\alpha$. Virology 259, 305-313 (1999).

17. Park, J. S. et al. Inactivation of interferon regulatory factor-1 tumor suppressor protein by HPV E7 oncoprotein. Implication for the E7-mediated immune evasion mechanism in cervical carcinogenesis. J. Biol. Chem. 275, 6764-6769 (2000).

18. Nees, M. et al. Papillomavirus type 16 oncogenes downregulate expression of interferon-responsive genes and upregulate proliferation-associated and NF-kB-responsive genes in cervical keratinocytes. J. Virol. 75, 4283-4296 (2001).

19. Campo, M. S. Animal models of papillomavirus pathogenesis. Virus Res. 89, 249-261 (2002).

20. Carter, J. J. et al. Comparison of human papillomavirus types 16,18 , and 6 capsid antibody responses following incident infection. J. Infect. Dis. 181, 1911-1919 (2000).

A longitudinal cohort study defining the slow and incomplete acquisition of antibody specific for HPVencoded capsid proteins and relating time of seroconversion to the onset of HPV infection.
21. Jochmus-Kudielka, I. et al. Antibodies against the human papillomavirus type 16 early proteins in human sera: Correlation of anti-E7 reactivity with cervical cancer. J. Nat Cancer Inst. 81, 1698-1704 (1989).

A cross-sectional study defining the prevalence of antibody to viral non-structural proteins in patients with invasive cervical cancer.

22. Campo, M. S. Animal models of papillomavirus pathogenesis. Virus Res. 89, 249-261 (2002)

23. Jarrett, W. F. et al. Studies on vaccination against papillomaviruses: the immunity after infection and vaccination with bovine papillomaviruses of different types. Vet. Rec. 126, 473-475 (1990)

24. Lin, Y. L., Borenstein, L. A., Selvakumar, R., Ahmed, R. \& Wettstein, F. O. Effective vaccination against papilloma development by immunization with $L 1$ or $L 2$ structural protein of cottontail rabbit papillomavirus. Virology 187, 612-619 (1992).

25. Ghim, S. et al. Spontaneously regressing oral papillomas induce systemic antibodies that neutralize canine oral papillomavirus. Exp. Mol. Pathol. 68, 147-151 (2000).

26. Nicholls, P. K. et al. Regression of canine oral papillomas is associated with infiltration of $\mathrm{CD} 4^{+}$and $\mathrm{CD} 8^{+}$lymphocytes. Virology 283, 31-39 (2001)

27. Arany, I. et al. Enhancement of the innate and cellular immune response in patients with genital warts treated with topical imiquimod cream 5\%. Antiviral Res. 43, 55-63 (1999).

28. Kadish, A. S. et al. Regression of cervical intraepithelial neoplasia and loss of human papillomavirus (HPV) infection is associated with cell-mediated immune responses to an HPV type 16 E7 peptide. Cancer Epidemiol. Biomarkers Prev. 11, 483-488 (2002)

29. Welters, M. J. P. et al. Frequent display of human papillomavirus type 16 E6-specific memory T-helper cells in the healthy population as witness of previous viral encounter. Cancer Res. 63, 636-641 (2003).

30. Höpfl, R. et al. Spontaneous regression of $\mathrm{CIN}$ and delayedtype hypersensitivity to HPV-16 oncoprotein E7. Lancet 356 1985-1986 (2000). 
A study showing a link between cell-mediated immunity to HPV non-structural proteins and regression of HPV-associated premalignant changes in the cervix.

31. Jarrett, W. F. et al. Studies on vaccination against papillomaviruses: a comparison of purified virus, tumour extract and transformed cells in prophylactic vaccination. Vet. Rec. 126, 449-452 (1990).

32. Zhou, J., Lu, W. J., Peng, S. W., Sun, X. Y. \& Frazer, I. H. Papillomavirus capsid protein expression level depends on the match between codon usage and tRNA availability. J. Virol. 73, 4972-4982 (1999)

33. Collier, B., Öberg, D., Zhao, X. M. \& Schwartz, S. Specific inactivation of inhibitory sequences in the $5^{\prime}$ end of the human papillomavirus type $16 \mathrm{~L} 1$ open reading frame results in production of high levels of $\mathrm{L} 1$ protein in human epithelial cells. J. Virol. 76, 2739-2752 (2002)

34. Frattini, M. G., Lim, H. B. \& Laimins, L. A. In vitro synthesis of oncogenic human papillomaviruses requires episoma genomes for differentiation-dependent late expression. Proc. Natl Acad. Sci. USA 93, 3062-3067 (1996).

35. Zhao, K. N. \& Frazer, I. H. Replication of bovine papillomaviru type 1 (BPV-1) DNA in Saccharomyces cerevisiae following infection with BPV-1 virions. J. Virol. 76, 3359-3364 (2002).

36. Zhou, J., Sun, X. Y., Stenzel, D. J. \& Frazer, I. H. Expression of vaccinia recombinant HPV $16 \mathrm{~L} 1$ and $L 2$ ORF proteins in epithelial cells is sufficient for assembly of HPV virion-like particles. Virology 185, 251-257 (1991). The first of a series of studies showing that expression of the HPV16 L1 capsid protein by eukaryotic cells from the second ATG initiation codon of the gene allows assembly of HPV VLPs.

37. Kirnbauer, R., Booy, F., Cheng, N., Lowy, D. R. \& Schiller, J. T. Papillomavirus L1 major capsid protein self-assembles into virus-like particles that are highly immunogenic. Proc. Natl Acad. Sci. USA 89, 12180-12184 (1992).

38. Chen, X. J. S., Garcea, R. L., Goldberg, I., Casini, G. \& Harrison, S. C. Structure of small virus-like particles assembled from the L1 protein of human papillomavirus 16 . Mol. Cell 5, 557-567 (2000).

39. Bell, J. A. et al. A formalin-inactivated vaccine protects against mucosal papillomavirus infection: a canine model. Pathobiology 62, 194-198 (1994).

40. Billich, A. HPV vaccine Medlmmune/GlaxoSmithKline. Curr. Opin. Investig. Drugs 4, 210-213 (2003).

41. Nardelli-Haefliger, D. et al. Specific antibody levels at the cervix during the menstrual cycle of women vaccinated with human papillomavirus 16 virus-like particles. J. Natl. Cancer Inst. 95 1128-1137 (2003).

42. Giroglou, T. et al. Immunological analyses of human papillomavirus capsids. Vaccine 19, 1783-1793 (2001).

43. Smyth, M. J., Godfrey, D. I. \& Trapani, J. A. A fresh look at tumor immunosurveillance and immunotherapy. Nature Immunol. 2, 293-299 (2001).

44. Peh, W. L. et al. Life cycle heterogeneity in animal models of human papillomavirus-associated disease. J. Virol. 76 10401-10416 (2002).

45. Han, R., Breitburd, F., Marche, P. N. \& Orth, G. Linkage of regression and malignant conversion of rabbit viral papillomas to MHC class II genes. Nature $\mathbf{3 5 6}$, 66-68 (1992).

46. Wang, S. S. et al. Human leukocyte antigen class I and II alleles and risk of cervical neoplasia: results from a populationbased study in Costa Rica. J. Infect. Dis. 184, 1310-1314 (2001).

47. Han, R. et al. DNA vaccination prevents and/or delays carcinoma development of papillomavirus-induced skin papillomas on rabbits. J. Virol. 74, 9712-9716 (2000). Evidence using the best available animal model of HPV associated malignancy that specific immunotherapy can alter the outcome of HPV infection.

48. Stanley, M. A. Progress in prophylactic and therapeutic vaccines for human papillomavirus infection. Expert Rev. Vaccines 2, 381-389 (2003)

49. Chen, C. H. et al. Gene gun-mediated DNA vaccination induces antitumor immunity against human papillomavirus type 16 E7-expressing murine tumor metastases in the liver and lungs. Gene Ther. 6, 1972-1981 (1999).

50. Ji, H. X. et al. Targeting human papillomavirus type 16 E7 to the endosoma//lysosomal compartment enhances the antitumor immunity of DNA vaccines against murine human papillomavirus type 16 E7-expressing tumors. Hum. Gene Ther. 10, 2727-2740 (1999).

51. Ji, H. X. et al. Antigen-specific immunotherapy for murine lung metastatic tumors expressing human papillomavirus type 16 E7 oncoprotein. Int. J. Cancer 78, 41-45 (1998).
52. Lamikanra, A., Pan, Z. K., Isaacs, S. N., Wu, T. C. \& Paterson, Y. Regression of established human papillomavirus type 16 (HPV-16) immortalized tumors in vivo by vaccinia viruses expressing different forms of HPV-16 E7 correlates with enhanced CD8 ${ }^{+} \mathrm{T}$-cell responses that home to the tumor site. J. Virol. $\mathbf{7 5}$, 9654-9664 (2001).

53. Velders, M. P. et al. Eradication of established tumors by vaccination with venezuelan equine encephalitis virus replicon particles delivering human papillomavirus 16 E7 RNA. Cancer Res. 61, 7861-7867 (2001).

54. Gunn, G. R. et al. Two Listeria monocytogenes vaccine vectors that express different molecular forms of human papilloma virus-16 (HPV-16) E7 induce qualitatively different T cell immunity that correlates with their ability to induce regression of established tumors immortalized by HPV- 16 . J. Immunol. 167, 6471-6479 (2001).

55. Gerard, C. M. et al. Therapeutic potential of protein and adjuvant vaccinations on tumour growth. Vaccine 19, 2583-2589 (2001)

56. Zwaveling, S. et al. Established human papillomavirus type 16-expressing tumors are effectively eradicated following vaccination with long peptides. J. Immunol. 169, 350-358 (2002).

57. Chu, N. R. et al. Immunotherapy of a human papillomavirus (HPV) type 16 E7-expressing tumour by administration of fusion protein comprising Mycobacterium bovis bacille Calmette-Guerin (BCG) hsp65 and HPV16 E7. Clin. Exp. Immunol. 121, 216-225 (2000).

58. Hariharan, K. et al. Tumor regression in mice following vaccination with human papillomavirus $\mathrm{E} 7$ recombinan protein in PROVAX. Int. J. Oncol. 12, 1229-1235 (1998).

59. Indrova, M. et al. Therapy of HPV 16-associated carcinoma with dendritic cell-based vaccines: in vitro priming of the effector cell responses by DC pulsed with tumour lysates and synthetic RAHYNIVTF peptide. Int. J. Mol. Med. 7, 97-100 (2001).

60. Stewart, T. J., Smyth, M. J., Fernando, G. J., Frazer, I. H. \& Leggatt, G. R. Inhibition of early tumor growth requires Ja18positive (natural killer T) cells. Cancer Res. 63, 3058-3060 (2003).

A paper showing that transplantable tumour models of immunotherapy of cancer in animals are susceptible to different types of immunotherapy, according to the maturity of the tumour.

61. Fernando, G. J. P., Stewart, T. J., Tindle, R. W. \& Frazer, I. H. $\mathrm{T}_{4}$ 2-type $\mathrm{CD} 4^{+}$cells neither enhance nor suppress antitumo CTL activity in a mouse tumor model. J. Immunol. 161, 2421-2427 (1998)

62. Gao, F. G. et al. Antigen-specific CD4+ T-cell help is required to activate a memory CD8 ${ }^{+} T$ cell to a fully functional tumor killer cell. Cancer Res. 62, 6438-6441 (2002).

63. Dunn, L. A. et al. Presentation of the HPV16E7 protein by skin grafts is insufficient to allow graft rejection in an E7-primed animal. Virology 235, 94-103 (1997).

64. Azukizawa, $\mathrm{H}$ et al. Induction of T-cell-mediated skin disease specific for antigen transgenically expressed in keratinocytes. Eur. J. Immunol. 33, 1879-1888 (2003).

65. Frazer, I. H. et al. Tolerance or immunity to a tumor antigen expressed in somatic cells can be determined by systemic proinflammatory signals at the time of first antigen exposure. J. Immunol. 167, 6180-6187 (2001).

66. Leggatt, G. R., Dunn, L. A., De Kluyver, R., Stewart, T. \& Frazer, I. H. Interferon- $\gamma$ enhances cytotoxic T lymphocyte recognition of endogenous peptide in keratinocytes without lowering the requirement for surface peptide. Immunol. Cell Biol. 80, 415-424 (2002).

67. Brady, C. S. et al. Multiple mechanisms underlie HLA dysregulation in cervical cancer. Tissue Antigens 55, 401-411 (2000).

68. Evans, M. et al. Antigen processing defects in cervical carcinomas limit the presentation of a CTL epitope from human papillomavirus 16 E6. J. Immunol. 167, 5420-5428 (2001).

This paper provides evidence that cervical cancer cells are selected for poor presentation of HPV-encoded antigens to the immune system.

69. Liu, X. S. et al. IL-10 mediates suppression of the CD8 $8^{+} \mathrm{T}$ cell FN $\gamma$ response to a novel viral epitope in a primed host. J. Immunol. 171, 4765-4772 (2003).

70. Pascual, D. W. Walters, N. \& Hillemeyer, P. Repeated intratracheal instillations of nonreplicating adenovirus 2 vector attenuate CTL responses and IFN- $\gamma$ production. J. Immunol. 160, 4465-4472 (1998).
71. Tindle, R. W. Immune evasion in human papillomavirusassociated cervical cancer. Nature Rev. Cancer 2, 59-65 (2002)

72. Connor, M. E. \& Stern, P. L. Loss of MHC class 1 expression in cervical carcinomas. Int. J. Cancer 46, 1029-1034 (1990)

73. Fowler, N. \& Frazer, I. H. Mutations in TAP genes are common in cervical carcinomas. Gynaecol. Oncology (in the press).

74. De Jong, A. et al. Enhancement of human papillomavirus (HPV) type 16 E6 and E7-specific T-cell immunity in health volunteers through vaccination with TA-CIN, an HPV16 L2E7E6 fusion protein vaccine. Vaccine $\mathbf{2 0}, \mathbf{3 4 5 6 - 3 4 6 4}$ (2002).

75. Goldstone, S. E., Palefsky, J. M. Winnett, M. T. \& Neefe, J. R. Activity of $\mathrm{HspE7}$, a novel immunotherapy, in patients with anogenital warts. Dis. Colon Rectum 45, 502-507 (2002)

76. Klencke, B. et al. Encapsulated plasmid DNA treatment for human papillomavirus 16-associated anal dysplasia: a Phase I study of ZYC101. Clin. Cancer Res. 8, 1028-1037 (2002).

77. Sheets, E. E et al. Immunotherapy of human cervical highgrade cervical intraepithelial neoplasia with microparticledelivered human papillomavirus 16 E7 plasmid DNA. Am. J. Obstet. Gynecol. 188, 916-926 (2003).

78. Borysiewicz, L. K. et al. A recombinant vaccinia virus encoding human papillomavirus types 16 and $18, \mathrm{E} 6$ and E7 proteins as immunotherapy for cervical cancer. Lancet $\mathbf{3 4 7}$, 1523-1527 (1996).

79. Davidson, E. J. et al. Immunological and clinical responses in women with vulval intraepithelial neoplasia vaccinated with a vaccinia virus encoding human papillomavirus 16/18 oncoproteins. Cancer Res. 63, 6032-6041 (2003).

80. Baldwin, P. J. et al. Vaccinia-expressed human papillomavirus 16 and $18 \mathrm{E} 6$ and $E 7$ as a therapeutic vaccination for vulval and vaginal intraepithelial neoplasia. Clin. Cancer Res. 9, 5205-5213 (2003).

References 79 and 80 show that development of immunity to HPV non-structural proteins after administration of vaccinia virus recombinant for the viral proteins to patients with HPV-associated anogenital malignancy is associated with partial resolution of disease.

81. Van Driel, W. J. et al. Vaccination with HPV16 peptides of patients with advanced cervical carcinoma: clinical evaluation of a phase I-II trial. Eur. J. Cancer 35, 946-952 (1999).

82. Frazer, I. H. et al. In Vaccines for Human Papillomavirus Infection and Anogenital Disease. (ed. Tindle, R. W.) 91-104 (Landes Bioscience, Austin, Texas, 1999).

83. Muderspach, L. et al. A phase I trial of a human papillomavirus (HPV) peptide vaccine for women with high-grade cervical and vulvar intraepithelial neoplasia who are HPV 16 positive. Clin. Cancer Res. 6, 3406-3416 (2000).

84. Zhang, L. F. et al. HPV6b virus like particles are potent immunogens without adjuvant in man. Vaccine $\mathbf{1 8}$ 1051-1058 (2000).

85. Ferrara, A. et al. Dendritic cell-based tumor vaccine for cervical cancer II: results of a clinical pilot study in 15 individual patients. J. Cancer Res. Clin. Oncol. 129, 521-530 (2003).

86. Frazer, I. H. et al. Immunotherapy for HPV associated precancer. Cancer Immunity 3, Suppl. 1, 25 (2003)

Acknowledgements

I thank K. Matsumoto, R. de Kluyver and G. Leggatt for permission to discuss their observations on the mouse skin-graft model of HPV infection before publication.

Competing interests statemen

The author declares competing financial interests: see Web version for details.

\section{(4) Online links}

\section{DATABASES}

The following terms in this article are linked online to:

LocusLink: http://www.ncbi.nlm.nih.gov/LocusLink/

IFN- $\alpha \mid$ IFN- $\gamma \mid$ IL-1 | |L-12

Entrez: http://www.ncbi.nlm.nih.gov/Entrez/

HPV16

\section{FURTHER INFORMATION}

Centre for Immunology and Cancer Research

http://www.cicr.uq.edu.au

Access to this interactive links box is free online. 